\title{
Sociocultural Beliefs and Women Leadership in Sanyati District
}

\author{
Christine Mwale \\ Bindura University \\ Obediah Dodo \\ Bindura University
}

\begin{abstract}
This study explored the level of women participation in leadership identifying some of the challenges thereto in the selected rural district of Sanyati, Zimbabwe. The study sought to address the following aspects: roles of women in Sanyati, sociocultural beliefs with regards to leadership, and the depth of the effects of women's nonparticipation in leadership. The research guided by the role congruity theory was qualitative in nature trying to understand human behavior and experience influenced by sociocultural norms. Research population composed of chiefs, headmen, village heads, elderly women and men, and councilors who had a sound appreciation of the subject. Twenty-seven participants, nine from each of the three wards, were purposively sampled and deemed enough as the research anchored on antipositivism. Data collection was necessitated through the use of in-depth interviews and questionnaires, after which latent content analysis was used to analyze data. The study established that the involvement and interest of women in leadership was low because of illiteracy, culture, and ignorance on the part of the women.
\end{abstract}

Keywords: culture, leadership, participation, illiteracy, development

\section{Introduction}

Women have been labeled as the weaker sex in most patriarchal societies, and this has affected all their spheres of life including leadership positions. Zunge (1996); Dodo (2013); and Dodo, Dodo, and Zihanzu (2017) believe that sociocultural beliefs have been a major hindrance to women's participation in leadership positions despite their capabilities and qualifications. It is therefore the scope of this study to explore the level of women participation in leadership and possibly identify some of the challenges thereto in the selected rural district of Sanyati, Zimbabwe.

\section{Background to the Study}

Sanyati District is in Mashonaland West province in Zimbabwe with a population of 113,220 (Sanyati Rural District Council, 2014). Of this population, 57,333 (50.6 \%) are males and 55,887 (49.4\%) are females. The district's area of jurisdiction is divided into 18 administrative wards represented by a councilor.

Even though the Zimbabwean government and civil society organizations are fighting for gender equality, Sanyati District has not yet made significant progress in that regard including women's advancement in leadership positions. Sociocultural beliefs and practices are blamed for women's failure to participate in leadership. According to Muchabaiwa, Chiminya, and Dodo (2010), the influence of gender stereotypes manifests in the form of low self-esteem and lack of confidence. 
Women also suffer from societal perceptions that their role in the family overrides all other roles and lack support from other family members. This is in spite of the fact that participation of women through gender equality has become a prominent issue at the global, national, and district levels through the enactment of laws, policies, and conventions. Muchabaiwa et al. (2010) further added that the participation of women in politics has emerged to be a critical issue around the world as it has been observed that women are heavily marginalized and excluded from the political sphere and yet they constitute over $50 \%$ of the world population.

Although sociocultural beliefs and practices are often blamed for barring women to access leadership positions, there are also some contemporary hurdles like illiteracy, lack of deliberate empowerment and lack of confidence on the part of women to take up challenge. In particular, Zimbabwe has signed and ratified conventions around participation of women in leadership besides crafting own laws and policies towards the same goal. These include the 1979 Convention on the Elimination of All Forms of Discrimination Against Women, the Beijing Platform for Action of 1995, the 2013-2017 National Gender Policy, and the 2013 Constitution of Zimbabwe. There is also the Millennium Development Goal Number 3, which promotes gender equality and women empowerment and the Southern Africa Development Community Protocol on Gender and Development (Southern Africa Development Community Gender Monitor, 2013).

The research examines the extent to which these sociocultural philosophies have affected women participation in key leadership positions especially in the district of Sanyati. The research is expected to be of importance in helping to review policies at various levels and map the position of women in rural societies with regards to leadership. The study also helps in making informed decisions on the discrimination of women and how best women could be empowered.

\section{Statement of the Problem}

Zimbabwe in general and Sanyati district in particular have not achieved the set millennium development goals target with regards to gender equality and the empowerment of women. Women in leadership in Sanyati have been noted to be very few, and yet demographically, they constitute the majority. Resultantly, most women are either struggling to access leadership or have long been pushed to the periphery through the use of patriarchal arguments. This state of affairs has been perpetuated largely through sociocultural beliefs systems.

\section{Objectives}

The study sought to identify the roles of women in Sanyati District and establish sociocultural beliefs and practices of the people in Sanyati District that have over the period affected the involvement of women in leadership at district and local government levels. In achieving the above objectives, the study sought to understand the definition of women from a cultural perspective in the area under study and what the local culture and traditions say about women and leadership beyond the household level. The study also sought to explore some of the most prominent barriers to the development and recognition of women in leadership.

\section{Area Under Study}

The study specifically focused on three wards: 10 (Nyimo), 11 (Wozhele), and 18 (Sanyati Growth Point). These wards stretch from Nyimo Business Center to Sanyati Growth Point bordering with Gokwe to the east and Munyati River to the south. The research selected these three wards because they are centrally located and representative enough of various ethnic and cultural practices in the 
District thus making the findings more generalizable, credible, and reliable. The three wards have a total population of 18,860 (Sanyati Rural District Council, 2014) constituting 16.7\% of the entire district population.

\section{Methodology}

The research was qualitative in nature seeking to understand human behaviors and experiences influenced by sociocultural norms. An exploratory design was used. It helped to discover and understand the interactions among different factors—social, cultural, and political—affecting women participation in leadership.

The research population was derived from traditional leadership: chiefs, headmen, village heads, elderly women and men, and councilors who had a sound appreciation of the subject. Convenient sampling was applied in the identification of participants to ensure that strategic members of the wards were selected for interviews. It also purposively selected traditional leaders. Twenty-seven participants, nine from each of the three wards, were sampled and deemed enough as the research anchors on anti-positivism.

Data collection was necessitated through the use of in-depth interviews as well as questionnaires. These tools sought to ensure quality and reliability of information through triangulation. Twelve questionnaires were distributed to literate traditional leaders while in-depth interviews were conducted with the other elderly participants. Latent content analysis was also used to analyze data. All the ethical research procedures were strictly followed to ensure that participants engaged voluntarily and aware of the implications thereto.

\section{Theoretical Framework}

The research was informed by the role congruity theory of prejudice toward females propounded by Eagly \& Karau (2002). This theory argues that perceived incongruity between the female gender role and leadership roles leads to two forms of prejudice: perceiving women less favorably than men as potential occupants of leadership roles and evaluating behavior that fulfils the prescriptions of a leader role less favorably when it is enacted by a woman (Heilman, 2001; Eagly \& Karau, 2002; Eagly, Beall, \& Sternberg, 2004). To some extent, African Renaissance theory also influenced the research.

The role congruity theory contends that gender stereotypes contribute to biased evaluations in leadership that women take care and men take charge (Dodge, Gilroy, \& Fenzel, 1995; Heilman, 2001; Hoyt \& Burnette, 2013). It is also argued that positions of power and influence in society have traditionally been occupied by men, whereas women have historically held lower status positions (Horyt \& Burnette, 2013). Resultantly, it has become difficult for women to become leaders and to achieve success in leadership roles especially in the developing world where information flow is slow and restricted.

\section{Literature Review}

\section{Cultures in Sanyati}

Sanyati is dominated by the Karanga-speaking people, and it is significant to note that the Karanga society is highly patriarchal, believing that women's place is in the kitchen and bedroom while men take all the leadership responsibilities. According to the Zimbabwe National Statistics Agency (2014), there are two chiefs in Sanyati who are all male, one male headman, and 18 councilors of 
whom 14 are male. According to Dodo (2013), there is still some resistance within the male traditional leadership on the appointment of females arguing it as uncultural. In the district, there are also pockets of other ethnic groups like the Ndebele to the south, Tonga to the north, and Zezuru in the east, which also have some influence on the cultural practices.

According to the Karanga culture, traditional leaders have the following duties: to promote and uphold cultural values of their communities, to promote sound family values, and to take measures to preserve culture. They also protect history and heritage of their communities, including sacred shrines, facilitate development, administer communal land and address disputes. However, the coming of contemporary governance has formalized some of the traditional leadership roles by crafting an Act of Parliament (Section 282[1]; Chigwata, 2014; Dodo, 2013).

\section{Leadership in Traditional African Societies}

According to Biri and Mutambwa (2013), African women have the following roles: woman, mother, and wife. Females are subordinated because of social, religious, and cultural practices and beliefs in the society. This is supported by Chigwata (2014), who said that during the formative years in African society, female and male children were taught some societal beliefs and practices that emphasized maleness above femaleness. These inhibited females' participation at all levels and in all spheres of development process. Therefore, performing leadership role in workplace becomes enormous due to the sociocultural practices and beliefs that affect the female gender negatively.

According to the social role theory as argued by Eagly and Karau (2002), individuals develop descriptive and prescriptive gender role expectations of others' behavior based on an evolutionary sex-based division of labor. In manner almost similar to most African cultures, Eagly et al. (2004) argued that division of labor has customarily related men with breadwinner positions and female with homemaker positions. Based on social roles, women are normally described and expected to be more communal, relations oriented, and nurturing than men, while men are believed and expected to be more assertive and independent than women. Women roles build upon social role theory by considering the congruity between gender roles and leadership roles. It is also argued that people tend to have different beliefs about the personality of leaders and women and similar beliefs about the personality of leaders and men (Dodo et al., 2017). This is supported by Abolade (2014) who argues that females are sandwiched between the patriarchal control of the males in the community and cultural demands that restrict them to the kitchen and the bedroom.

\section{Traditional Leadership in Shona Societies}

The Shona culture is a conservative patriarchal society that values its culture, norms, and beliefsat the end shaping one's behavior. According to Bhila (1982) and Dodo (2013), traditional leadership has been dominated by men, and these leadership systems have been to some extent responsible for the pathetic conditions of women up to this day. In the Shona culture, there are a lot of misapprehensions adjacent the physical make up of different sexes. Tatira (2000) argued that women are believed to be physically weaker than male members so much so that women are encouraged to consult. There is also a myth that women need men by their side to excel (Biri \& Mutambwa, 2013).

Socialization is the reason why women's positions in society continue to be discounted while men's roles and positions are upheld. This has hindered women in accessing key leadership positions as the platform is considered for men only. Tatira (2000) and Rutoro (2013) further argued that women who make it to the leadership positions outside the perceived feminine roles may be accepted as unique, exceptional, and unrepresentative of women in general. Generally, while women are believed to have 
often occupied a back seat in leadership, there have been several women leaders in traditional societies as aptly posited by Bhila (1982) and Dodo et al. (2017) who cited the appointment of headwomen by King Tendai in Manyika State and the existence of Nyamandoto and Mativirira spiritual leaders in the Teve and Mutapa States, respectively.

\section{Perception of Women Leadership in Modern Societies}

There is a debate among scholars (Biri \& Mutambwa, 2013; Elliott \& Stead, 2009; Gaidzanwa, 1992) on female leaders as some view women as being incapable of being leaders and that they need men by their side. However, some are of the view that women can be good leaders compared to men (Gaidzanwa, 1992; Zinyemba, 2013). The situation of women in Zimbabwe before independence shows that culture negatively influenced participation of women in leadership positions. There is also an argument that young women are discriminated in decision-making institutions at local governance level compared to young men. Richard and Koredong (2015) argued that young women are underrepresented in leadership roles that do exist for women.

\section{Women Leadership and Their Challenges}

In Zimbabwe, the way traditional sociocultural and religious ethics bind women inevitably affects development at all levels (Biri \& Mutambwa, 2013). According to Ngan (2011), both the indigenous and organizational culture substantially influence the female participants' exercise of leadership and, consequently, contribute to the poor representation of women in leadership positions.

Both Rutherford (2001) and Ngan (2011) maintained that women face barriers on their way to the top positions, and while in those positions they may experience unequal employment opportunities and role conflict as well as patriarchal attitudes towards women. Research has confirmed that cultural context is a significant factor in women's perceptions about responsibilities and family life balance (Tein, 2010). The fact that most women manage households including the welfare of children implies that there are some social responsibilities that they cannot assume. There are also some jobs and roles that require strong physique, which, in most cases, is not existent in women.

\section{Findings and Discussion}

Data were presented responding to specific objectives as outlined above. The discussion is also concurrently done with the presentation of data for ease of analysis. The analysis of the interviews and questionnaires was done separately allowing the consideration of participants' mannerisms, emotions and gestures. However, the presentation of the results is simultaneously done following particular themes.

\section{Sociocultural Beliefs of People in Sanyati District}

Seven traditional leaders highlighted that sociocultural belief systems in the Shona people were very conservative. Seven participants indicated that the Karanga people believe that women are helpers and not leaders. These participants also believed that women's place is in the kitchen and that women are there to help their male counterparts not to lead men. Four others revealed that they were ambassadors in upholding cultural values of the people in Sanyati. They added that Sanyati is a highly patriarchal society with the Karanga being the major group. 
One male traditional leader had this to say:

\begin{abstract}
Madzimai pasichigare vaizviisa pasi pane zvose vaisatora zvigaro zvehutungamiri zvepamusoro kubva muBhaibhiri vakasikwa sevabatsiri. Hazvibviri kuti ukatsvaka mubatsiri pamba pako angauya achizokutonga kwete, iwe muridzi wapamba ndiwe unomuudza zvokuita, zvimwechetezvo nomunhukadzi Mwari pachavo pavakasika Eva vakati kuna Adam ndava kukusikira mubatsiri vachireva munhukadzi.
\end{abstract}

(Women even long back they did not occupy positions of influence from the Bible, imagine you hire a maid will he/she tell you what to do at your house? You as the house owner is the one who gives instructions to the maid, the same applies to women when God created Eve he said to Adam, I have created for you a helper referring to females.)

It is apparent from the participants' contributions that marginalization of women in leadership positions emanated from conservative elements and practices contained in the culture of the Sanyati society, as explained by Ngan (2011) and Biri and Mutambwa (2013). Social structures have for a long time created a discriminatory practice on the appointment of women into leadership positions. This is supported by Dodo (2013), who alludes that traditional leadership has been dominated by men and these leadership systems were to some extent responsible for the pathetic conditions of women up to this day. Culture has been used to socialize that men are the leaders and women follow, clearly reminiscent of the argument by the role congruity theory of prejudice.

Men in Sanyati District, according to 16 participants, view themselves as superior to women. These participants argued that men owned properties and managed homes while women could only superintend daily affairs. However, there were also dissenting voices from the female side who argued that while they wanted to partake in leadership and development issues, there were some men who continually blocked them. One female participant said,

Vanhurume havadi kutungamirirwa nevanhukadzi vanowanikwa vachitidzikisira vanotendera kuti hutungamiri ndewevanhurume.

(Males do not want to be led by females they tend to underestimate the value of women in leadership positions.)

Three other female elderly participants indicated that societal beliefs and culture influenced leadership selection in Sanyati District. These participants stated that the beliefs and teachings inculcated in the local people hindered women to assume key leadership responsibilities. One female participant said,

The major challenge faced by women leaders is their men subjects in society. Most male subjects believe they cannot be led by women; they claim that men should be the leaders. Some of them try by all means to expose women by giving them difficult topics in public spheres when addressing people. Most of the time, women are given platforms on minor events so that people do not recognize them.

Fifteen participants argued that women and men are socialized differently. They argued that culture is not uplifting women to leadership positions because it pictured a male figure having an authoritative position in society. This is evidenced by some beliefs in the Karanga society that the leadership arena is meant for men. Any women who want to join are regarded to be uncultured as argued by Rutherford (2001) and Chigwata (2014). 
One male participant had this to say:

Patsika dzedu vanakomana nevanasikana vane tsika dzavanodzidziswa dzinoenderana namabasa avanofanira kuita pamagariro echivanhu, vanasikana vanodzidziswa mabasa akaita sokurera vana nokuita mabasa apamusha, vanakomanawo vanodzidziswa kuva vatungamiri vemhuri.

(In our culture girls and boys are socialized differently, girls are taught how to take care of children and other household chores while boys are taught how to look after the family.)

\section{Roles of Women in Sanyati District}

Twenty three participants highlighted that the roles of women in Sanyati District were domestic. These roles include being mothers, wives, cooking, going to the fields, looking after children, advisors on cultural practices in society, washing clothes, herding cattle, supporting male counterparts with ideas, gardening, bearing children, poultry keeping, and promoters of peace.

One traditional leader said;

Nzvimbo yavanhukadzi iripamba, basa ravo kuchengeta varume vavo, kurera vana nokuita mabasa apamusha anosanganisira kuwacha, kusuka nekurima miriwo.

(The place of women is home. Their duty is to look after their husbands and rearing children and attending to other roles such as washing, doing dishes and gardening among others).

This is further supported by what one male elderly participant said:

Vanhukadzi kubva pasi chigare basa ravo raiva rapamusha, kudare kwaiva ndiko kunotongerwa dzimhosva yaiva nzvimbo yavanhurume bedzi.

(Women even long ago their roles where at the house, the court where crimes were judged was the place for men only.)

Eleven traditional leaders indicated that the traditional culture in Sanyati District did not allow gender equality in terms of appointments to key positions. Therefore, as long as the culture is not revisited, women might remain in the periphery and continue to be marginalized in district's governance. An elderly participant said,

Vakadzi vanemabasa akawanda avanoita pamusha naizvozvo havakwanise kuzoita basa rokutungamira zvakanaka.

(Women have many household chores therefore they can perform well in leadership.)

In traditional African society, the survival of the family and the future of marriage depended a great deal on the African woman. Gaidzanwa (1992) argued that women have traditionally played an invaluable role in society; it was also gathered that women are pivotal in the sustenance on most marriages and the rearing of children. This is supported by one elderly man who said,

Vanhu mudunhu vanotsigira hutungamiri hwevanhukadzi nokuti pasichigare taitova nemadzimambo echikadzi akaita sanambuya Nehanda vakatotungamira zvakanaka munguva yehondo. 
(People in this District support women leaders as we had great female leaders such as Nehanda during the 1890s' liberation struggle.)

It was also noted that although most participants indicated that women had no place in leadership, 12 participants had a different view arguing that women nowadays were being involved in leadership assignments though on a smaller scale. It was explained that society appreciated women leaders, though most men still had the perception that males are the only good leaders.

Eleven male participants indicated that some men did not have trust in women leadership as they often expressed some sense of confidence inadequacy. Six female participants indicated that some male traditional leaders are of the view that women cannot be given leadership posts in the district because they lacked confidence. The six participants also indicated that women are naturally weak as highlighted by the role congruity theory of prejudice. They also indicated that some women believed that they cannot lead men hence they always nominate men to lead them. It is therefore observed that the perception of male privilege resulting from a patriarchal culture and the socialization process creates internal barriers for women such as lack of confidence and lack of motivation.

However, five elders agreed that female leaders have the potential to lead because of their motherly traits. They stated that women are more committed to their duties as they have patience to listen to community concerns. They also indicated that female leaders are traditionally naturally less corrupt than their male counterparts. One participant had this to say:

Vanhukadzi tinovada kuti vave vatungamiri nokuti havana huori, vakavimbika kudarika vanhurume uye zvose zvavanoita vanoita vaine vanhu pamoyo yavo nokuti ndivanaamai zvakare.

(We want women to be leaders because women leaders are less corrupt than their male counterparts and their decisions are made with people at heart because they are mothers.)

\section{Barriers Faced by Women}

Twenty-two participants reported that there are cultural and legal barriers that affected the ascendency of women into leadership. They indicated that women are socialized to believe that men are there to lead and women act as subordinates. They added that while there were laws to support female ascendency to leadership, there was no effective implementation to ensure the application and attainment of the goal at local government level. Ten participants alluded to the fact that culturally women are inferior to men and therefore unfit to lead.

One traditional chief confirmed through an interview,

Hutongi hwamasadunhu nemasabhuku ndewedzidza naizvozvo haugone kugadzwa mwanasikana mumhuri nokuti anozororwa achienda nahwo kunerimwe dzidza zvisiri mutsika dzedu.

(Leadership of chiefs and headmen cannot be granted to a girl child due to the fact that she can be married and take the leadership post to another tribe which is not in our culture.)

It was observed that Sanyati District still holds onto its culture, which is patriarchal, though there are some policies that have been put in place by the government to help and promote the development of women into leadership circles. Five participants also pointed out that women did not 
support each other ascend into leadership even if they were given the platform. Mostly women were culturally socialized to believe that they are not competent enough to lead.

This was supported by one councilor:

Vakadzi pachavo havatsigirane chero tikada kusarudza vanotungamirara WADCO vakadzi vanongodoma varume.

(Women do not support each other even if we want to select a WADCO [ward development committee] representative, women nominate men.)

Thirteen participants revealed the fact that culturally women do not own property. Therefore, it is a disadvantage when it comes to contesting for leadership positions, because the laws require that contestants own some immovable properties for legibility to contest. The 13 participants indicated that communities in Sanyati preferred rich people, arguing that they are less corrupt as they do not use public resources to enrich themselves.

It was revealed by 11 participants that women are often exposed to sexual abuse when trying to attain leadership positions. Three female elderly participants highlighted that women leaders are affected by marriage demands. Marriage is a significant cultural barrier contributing to marginalization of married women leaders. Though the communities might want to give them key posts, it has been observed that women have serious responsibilities at home that giving them higher tasks might also overburden and affect their families. Family and societal hierarchical structures also force women to occupy lower positions in society as posited by Ngan (2011). This has psychologically impacted on the female candidates for leadership.

\section{Discussion}

The research established that there were a variety of factors behind the nonparticipation of women in leadership matters in society especially in the rural Sanyati District. The study found out that marginalization of women in leadership positions emanated from conservative elements and practices contained in the culture of the people in Sanyati as explained by Ngan (2011) and Biri and Mutambwa (2013). However, despite this noted discrimination, there are some few women who have managed to climb up the ladder. A case in point is that of the four councilors in the Rural District Council.

As per the Karanga culture, women and men are socialized differently. Therefore, most participants noted that the form of socialization clearly allotted responsibilities to the two constituencies differently and according to what their culture told them; men take up leadership positions, while women look after their homes and children. Because of the patriarchal belief system, any women who attempt to join leadership ranks are regarded to be uncultured as argued by Rutherford (2001) and Chigwata (2014). Clearly, this shows the existence of the role congruity theory of prejudice aspects.

On the roles of women, the study established that women basically play the following household chores: mothers and wives, cooking, going to the fields, looking after children, advisors on cultural practices in society, washing clothes, herding cattle, supporting male counterparts with ideas, bearing children, poultry keeping, and promoters of peace among others. Traditionally, and because of the societal and political restrictions, women have remained closed in such backward and supportive paradigms. According to views by the traditional leaders, the traditional culture in Sanyati District did not allow gender equality in terms of appointments to key leadership positions. 
Therefore, as long as the culture is not revisited as argued by Gaidzanwa (1992), women might remain in the periphery. In this study area, women may remain exercising their influence within their households unless there are deliberate interventions from a cultural perspective. According to the study, the emancipation of women can only be achieved through appropriate education, empowerment and acknowledgement of the women's progressive roles in society as demanded in the African Renaissance theory.

It has to be realized that women sometimes fail to successfully take up other social and leadership roles because of other pressing household responsibilities; otherwise, they could produce excellent leadership. What however clearly came out of the participants' responses is that, at individual level, gender equality is a necessity and progressive. It is only a challenge if it is viewed from a collective standpoint where cultural implications are then pushed to the front.

The study established that there were both cultural and legal barriers that affected the ascendency of women into leadership. However, it requires concerted effort from both the traditional and political spheres to appreciate the capabilities of women in leadership circles before a deliberate drive towards the empowerment of women is initiated. This however requires the acknowledgement of the dictates around the role congruity theory of prejudice to achieve the goal.

\section{Recommendations}

There is need for concerted efforts in Sanyati to empower women in accordance to the National Gender Policy so that they take part in leadership as there are also female councilors in Sanyati District. There is need for the community to unite and strive to disband some of their archaic cultural philosophies and norms that do not support women involvement in leadership.

Gender roles that objectively discriminate women from leadership should be discarded. A new approach that promotes women leadership should be implemented through advocacy for neutral roles and equality for everyone. Women should be encouraged and supported to participate in leadership preparation and training program so that they feel more self-confident and function effectively once appointed.

The institution of marriage should be redefined to promote equal decision making for both partners. Both men and women in Sanyati should be educated and reoriented to view their marriage institution as an institution in which both have equal powers of decision-making. This can help in restoring confidence in women so that they can also have a say in district decision-making bodies and processes.

\section{Summary}

The research established misconceptions surrounding the physical makeup of different sexes. The belief that men are culturally suitable for leadership because of their physical strength has disadvantaged women in development. This division of labor among men and women in Sanyati furthers these misconceptions thus affecting women ascension into leadership.

The Karanga culture in Sanyati District also promotes female submission and male autonomy, which leaves females at the mercy of their male counterparts. There are also challenges around culture, marriage, payment of lobola, and also the fact that culturally women do not own property. The Karanga culture in Sanyati District also determined the proximity to power bases. It was seen that culture in Sanyati District places males within the leadership circles from childhood. The research also found out that rights to property were seen to affect the motivation of women into key 
leadership positions. However, main solutions to these challenges lie in education and formulation of positive policies by the responsible authorities.

\section{References}

Abolade, D. A. (2014). Impacts of industrial democracy on organizational performance (case study of selected private and public sector organizations in Lagos State, Nigeria). Journal of Research in Social Sciences, 3, 11.

Bhila, H. H. K. (1982). Studies in Zimbabwean history: Trade and politics in the Shona Kingdom: The Manyika and their Portuguese and African neighbours, 1575-1902. London, United Kingdom, Longman.

Biri, K., \& Mutambwa, J. (2013). Sociocultural dynamics and the empowerment of women in Zimbabwe: Educating women for sustainable development. African Journal of Social Work, $3,19-36$.

Chigwata, T. (2014). The role of traditional leaders in Zimbabwe: Are they still relevant? Law Democracy and Development, 20, 69-90. doi:10.4314/ldd.v20i1.4

Dodge, K. A., Gilroy, F. D., \& Fenzel, L. M. (1995). Requisite management characteristics revisited: Two decades later. Journal of Social Behaviour and Personality, 10, 253-264.

Dodo, O., Dodo, G., \& Zihanzu, M. (2017). African women in traditional leadership role in Zimbabwe: The case of Shona. African Journal of Democracy and Governance, 4, 133-158.

Dodo, O. (2013). Traditional leadership systems and gender recognition: Zimbabwe. International Journal of Gender and Women's Studies, 1, 29-44.

Eagly, A., \& Karau, J. S. (2002). Role congruity theory of prejudice toward female leaders. American Psychological Association, 109, 573-598.

Eagly, A. H., Beall, A., \& Sternberg, R. S. (Eds.). (2004). The psychology of gender (2nd ed.). New York, NY: Guilford Press.

Elliott, C., \& Stead, V. (2009). Women's leadership. London, United Kingdom: Palgrave Macmillan.

Gaidzanwa, R. (1992) Bourgeois Theories of gender and feminism and their shortcomings with reference to southern African countries. In R. Meena (Ed.), Gender in Southern Africa: Conceptual and theoretical issues (pp. 111-128). Harare, Zimbabwe: SAPES.

Heilman, M. E. (2001). Description and prescription: How gender stereotypes prevent women's ascent up the organizational ladder. Journal of Social Issues, 57, 657-674.

Hoyt, C. L., \& Burnette, J. L. (2013). Gender bias in leader evaluations: Merging implicit theories and role congruity perspectives. Personality and Social Psychological Bulletin, 39, 1306-1319.

Muchabaiwa, B., Chiminya, J., \& Dodo, O. (2010). Strategies and politics of development (DS104). Harare, Zimbabwe: Zimbabwe Open University.

Ngan, L. (2011). How does culture impact on women's leadership in higher education? A case study in Vietnam (Master's thesis). University of Waikato, Hamilton, New Zealand.

Richard, E., \& Koredong, I. (2015). Bougainville young women's leadership research. New Caledonia, Australia: International Women Development Agency.

Rutherford, S. (2001). Any difference? An analysis of gender and divisional management styles in a large airline. Gender Work and Organisation, 8, 326-345. 
Rutoro, E. (2013), Vestiges of sexism and gender stereotyping: ZIMSEC ordinary level English language examinations from 2007 to 2012. International Journal of Education and Research, $1,1-16$.

Sanyati Rural District Council. (2014). Sanyati rural district wash strategic plan 2014-2019 (unpublished).

Southern Africa Development Community Gender Monitor. (2013). Women in politics and decisionmaking. Gaborone, Botswana: Author.

Tatira, L. (2000). Zviera ZvaVaShona [Taboos of the Shona people]. Gweru, Zimbabwe: Mambo Press.

Tein, O. A. (2010). Power and womanhood in Africa: An introductory evaluation. The Journal of Pan African Studies, 3, 229-238.

Zimbabwe National Statistical Agency. (2014). National Periodic Updates on Households. Harare, Zimbabwe: Author.

Zinyemba, A. (2013). Impact of culture and gender on women managers in the hospitality and financial services in Zimbabwe. International Journal of Advanced Research in Management and Social Science, 2, 34-47.

Zunge, M. S. (1996). Researching gender in a palestinian camp: Political, theoretical and methodological issues. London, United Kingdom: Macmillan.

The Journal of Social Change, sponsored by Walden University, welcomes manuscripts focusing on interdisciplinary research in social change that improves the human condition and moves people, groups, organizations, cultures, and society toward a more positive future.

Walden University Publishing: http://www.publishing.waldenu.edu 